\title{
EDUCATION AS AN EMPLOYEE MOTIVATION AND RETENTION FACTOR OF BANKS AND FINANCIAL COMPANIES OPERATING IN THE CZECH REPUBLIC
}

\author{
Němečková, I.
}

This article addresses the human potential of companies as well as the motivation and retention of employees, which play a key role in reaching a company's commercial and financial goals. The article's objective is to answer questions concerning employee education as a significant tool of employee motivation and retention in the financial sector. The initial part of the article deals with the theoretical background of employee motivation and retention, methodology, and hypotheses setting. Verification of the hypotheses should lead to objective achievement by their confirmation or refusal. The hypotheses were verified and confirmed through empirical research; the author conducted research among employees of financial companies in the Czech Republic. The research was supplemented by round table discussions with the respondents. A clear result has come of the research; financial sector employees valued further education the most out of eighteen offered benefits provided by employers. The article's provides managers with recommendations.

JEL Classification: M5

\section{Introduction}

Motivation is defined as an objective - directed behavior of an individual (Armstrong, 1999). Motivation is not a constant but rather it develops over the whole human life cycle. Many theories deal with work motivation, starting in the early $19^{\text {th }}$ century. The majority of them try to explain what motivation is, where it comes from, and how it develops.

A prevailing majority of the theories were created by American psychologists. Starting from classical motivational theories, we proceed through new scientific findings to contemporary modern theories looking at a human as a scientific model.

The first theories (for instance, the Theory of Instrumentality) have their roots in the methods of F. W. Taylor, the founder of scientific management. Many of the oldest theories were based on instincts, supported by personality psychodynamic theories. A. H. Maslow started to work with this term and replaced it with the word need in his well-known Hierarchy of Needs theory. Other theories followed, for example Behavioral Theory of B. F. Skinner, Herzberg's Two Factor Theory of work motivation, ERG theory of Alderfer, Y theory of D. McGregor and others (Landy, Conte, 2010). In the $20^{\text {th }}$ century, so-called process theories (Kanfer, Chen, Pritchard, 2008) influenced the area of work motivation and this direction was further expanded by American psychologist Victor Vroom in his Expectancy Theory VIE (Landy, Conte, 2010).

Modern theories deal with a human being as a scientific model - for instance, the Theory of Goal Setting by Locke and Latham (Locke, Latham, 2002); this approach continues to be further utilized by numerous authors even now. It is impossible to omit the Theory of Control and the concept of self-regulation by Vancouver (Vancouver, 2005), the Theory of Self-efficacy (Bandura, Locke, 2003) or Expectancy theories, for example from Frese and Sabini.

Successful company managers evaluate investments and all expenses very responsibly all of the time, especially in the current difficult times of the global economy. It impacts a wide variety of benefits used traditionally by financial companies for their employees because they are aware of the direct influence of employee motivation, as for example mentioned by Jon-Chao Hong, Sung-De Yang, Li-Jung Wang, En-Fu Chiou, Fan-Yin Su, and Sui-Lan Huang in their article "Impact of employee benefits on work motivation and productivity" (Hong, 
Yang, Wang, Chiou, Su, Huang, 1995). The growing importance of benefits is also stressed by B. T. Beam and J. J. McFadden in their book "Employee Benefits" (Beam, McFadden, 2001). The questionnaire research done by the author among employees of financial institutions (banks and investment companies) in the Czech Republic has confirmed an alarming finding - 95.7\% of respondents stated during round table discussions, irrespective to their position in a company's hierarchy, that they had noted cost cutting in the area of education and training, including specialized language courses as well as professional conferences. This is disturbing information, taking into account for instance the finding of authors Joo and Grable in their article "Improving Employee Productivity” (Joo, Grable, 2000) on the direct link between work productivity and education.

The success of every subject active in the competitive environment is dependent on many external factors, either on the macroeconomic or microeconomic level; this includes third parties like the state administration, public opinion and related Corporate Social Responsibility influences as well as internal factors directly related to the specific situation inside of each such subject, which can be - up to a certain extent - influenced by the subject itself.

Human potential is a key success factor for every company in the competitive environment. Every company has human potential at its disposal, and it differentiates it from the other competitors active in the same field of business. Professional and managerial capabilities, the knowledge and experience of managers as well as the erudition of ordinary employees with their individual capabilities in the company's work distribution, company culture and general creative atmosphere in companies are factors with an ultimate influence on the success and prosperity of comparable companies active in the same field of business. It is not enough to gather relevant employees but the proper motivation for reaching their goals must be secured and by that their retention in a given company. This should be - and in many companies, it is - one of the key tasks of every manager's personnel responsibilities, regardless of their management level, i.e. it should not only be the task of managers responsible for human resources.

Let's not forget that employees' good quality results have a direct impact on the satisfaction of an organization's clients and partners as well as the commercial and financial success of the company; the resulting satisfaction of both owners and employees closes an entire virtual circle. The harmony of a company's goals with each employee's goals is a basic prerequisite for company success and prosperity; as such, there should be effort by every company's management to motivate employees as much as possible and simultaneously to retain them. Motivation and retention issues are very complicated; this results from the individuality of every man with his specific needs and priorities. In connection to this, it is necessary to mention also the fact that, unlike the majority of an organization's other business tools, the quality of its human resources cannot be changed overnight. Human capital, as a part of intellectual capital, can be very quickly lost by mismanagement of human resources and therefore it is in the interest of every company and its management to focus all attention not on what clients of the company require today but what will be required in the coming years (Kleibl et al., 2005).

\section{Article's objectives and defined hypotheses}

The article's objectives are to provide answers to questions regarding whether education is an important employee motivation and retention tool in financial sector companies, what role it plays in their professional life and whether it can also impact client satisfaction.

The way to reach the article's objectives was definition of the hypotheses and their consequent verification by means of empirical research complemented by round table discussions with respondents carried out by the author within the framework of employee motivation and retention research in financial companies active in the Czech Republic.

H1: It is possible to find out and term key factors preferred by employees in the Czech Republic out of benefits offered by financial companies to them.

$\mathrm{H} 2$ : The possibility of further education and professional growth is a very important motivational factor for employees.

\section{Research methodology}

The research objective was to find out respondents' opinions about benefits and their influence on work motivation and retention via use of empirical research in banks and investment companies active in the Czech Republic. Questionnaire research was selected as the key tool; as a complementary method, round table discussions - with a task to verify and specify results of the questionnaire research - were used.

There were a total of 142 respondents participating in the anonymous research; this number provides sufficient reliability of the results. The respondents' structure respected balance in gender (57.1\% female, $42.9 \%$ male), age ( $41.2 \%$ below 33 years, $49.6 \%$ between 34 
- 50 years, 9.2\% above 51 years), education (68.1\% university graduates, 31.9\% high school graduates), social status (56.3\% single childless, 40.3\% married parents, $1.7 \%$ single parents without child, $1.7 \%$ single parents with child), employment period (40.3\% below 3 years, 37\% between $4-10$ years, 22.7\% 11 years and more), jobs (50.4\% administration, $11.8 \%$ IT, $15.1 \%$ commercial, 8.4\% dealing, $7.6 \%$ top management, 6.7\% risk management and analyses) and their position in the company hierarchy (41.2\% independent specialists, $31.1 \%$ ordinary employees, $16.8 \%$ middle management, $10.9 \%$ top management).

The respondent group consisted of 41 employees from one bank, 36 employees from an investment company and 42 employees from various other banks and investment companies.

In total, 23 respondents participated in round table discussions, split into four separate groups. The first round table involved six employees holding various jobs at one bank; the second round table involved six employees holding various jobs at an investment company. Six employees from various ordinary and specialist positions at different companies participated in the third round table discussion, and five managers from various companies participated in the fourth round table discussion.

The method was selected irrespective of various obstacles accompanying it (difficulty to gain such a number of respondents, demanding data processing and evaluation, creation of a questionnaire with as wide as possible extent of items related to employee motivation and retention, responsible completion by the respondent, etc.) because the author proceeded from an assumption that employees are able to identify and consequently communicate the factors that influence their motivation and retention.

The questionnaire focused on benefits consisted of 18 items and respondents' task was to sort all offered items as per their importance, from a personal perspective, from the most important down to the least important. The methodology was based on order of the items provided by the respondents and their weight shown in percentage.

\section{Research results}

The respondents were asked to sort anonymously 18 benefit items usually offered by companies in the questionnaire based on their importance from the most important and interesting down to the less attractive ones. The respondents decided among the following benefits: contribution to pension scheme, life insurance, healthcare, vacation, culture and sport activities and meals, sick days, contribution to language courses, further education, professional internships, relaxation during the working day, mobile phone for private use, Internet, notebook, free legal advice, psychologist services, organization of holiday trips, laundry and cleaning services.

The questionnaire research brought convincing results proving how important benefit education and training is for employees in their work motivation and retention in a given company irrespective of their job, age or education level (the respondents were exclusively graduates from secondary schools or universities). There are also no employees with only an elementary education in financial institutions because services requiring only a low qualification (maintenance, cleaning, etc.) are usually supplied by specialized outsourced companies. Use of the round table method, originally planned as a complementary method to the questionnaire research, proved to have a significant importance. It helped to confirm and specify respondents' opinions on individual benefits' importance and additionally also confirm an assumption that employees registered significant cost cutting in the area of education and training during the economic crisis.

The research results showed, in third place, language education paid by the employer (9.2\% out of all 18 benefits) as most important right after sick days and pension scheme contribution. The employer's contribution to education and trainings gained the sixth position (7.6\%) and the possibility of professional domestic and foreign internships was ranked in the eleventh position (5.5\%). The total sum of percentages received by "contribution to language education", “contribution to education" and "professional internships" amounted to $23 \%$ by which the total items covering education and professional growth amount to almost one quarter of all offered benefits.

The research results (with regard to the gender split of respondents) show that the possibility of further education financed by the employer received a considerably higher score from women (24.1\%) than from men (19.2\%). If we look at the results split by the highest reached education, the respondents with secondary education prefer the evaluated benefit more (19.2\%) than those with a university degree (18.3\%). If we look at the results split by age groups, the highest interest was reported by the group of employees aged 33 years (23.5\%), followed by the employees in the age interval of 34 - 50 years $(22.1 \%)$ and by employees older than 50 years at the end (18.3\%). The research showed that respondents, as split by their job position in the 
Figure 1: Importance of employee education for their work motivation

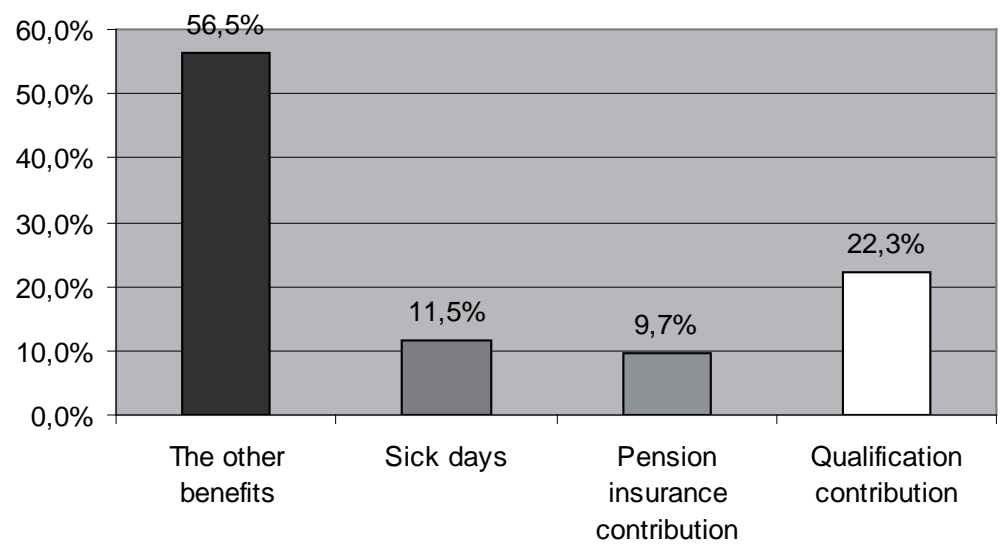

Source: author's empirical research

Figure 2: Importance of education for work motivation, by type

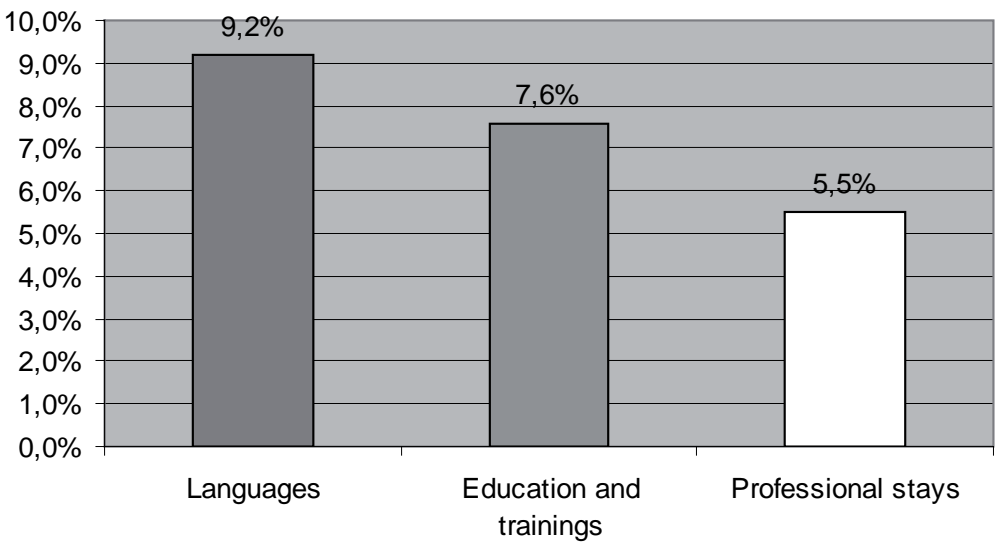

Source: author's empirical research

company hierarchy, in the group of middle management (24.6\%) assign the highest importance to the possibility of education, followed by specialists (23.6\%), ordinary employees (23.4\%) and top management (8.3\%). It confirms that top managers are usually well equipped with language skills and further language education is thanks to regular language usage - not needed as it was confirmed during discussions in the round tables; in addition, many of them are graduates from prestigious universities and higher degree programs. It, however, doesn't mean that they shouldn't be further educated and expand on their specializations; nevertheless, the fact is that they have absolutely no time for these activities with respect to their heavy workload. This was also confirmed in the round table discussions.

Why are employees interested in further language and professional education? There are multiple reasons but awareness of the need to further grow professionally by every employee is the most noticeable of them. Professional growth ensures them the chance of their own employability, i.e. the ability to find a new job at any time. This does not always need to be with a new employer either, but it can also be with a current employer too. In addition, the financial sector in the Czech Republic went through direct confrontation with foreign companies right after 1989 and further education and trainings, along with gathering new experience and capabilities, were a must for the overwhelming majority of employees. The employees realized that they must become more flexible and able to adapt to new conditions in order to remain competitive; therefore, they were pressed to further educate themselves. In connection to this, there is an explanation that the employees have gotten so used to further education and frequent trainings that today, they consider them as almost an automatic part of their professional lives. 


\section{Recommendations to company managers}

The above mentioned research showed very persuasive results confirming the importance of further education provided, or at least enabled, by employers for employees in connection with their work motivation. It's an undisputable fact that cost cutting just in the field of employee further education and professional growth will appear in accounting books as an immediate savings. However, a negative effect of this step will be evidenced by a decrease in employee professional knowledge and capabilities, decreased motivation and resulting company destabilization visible in the worsening of client services and possibly a negative impact on a company's economic results in the long-term horizon.

It is relevant to stress a recommendation to company managers to reconsider the consequences of such savings in the area of employee further education. A possible solution could be to stop, in crisis times, general mass trainings but switch to a more tailor-made approach to education - specific trainings for specific job positions and specific employees. Thus the company's cost would decrease and simultaneously the necessary systematic educational process of the company would be continued. After all, what is a bigger asset for every company than educated, professional, motivated and thus retained employees?

\section{Conclusion}

Finally, it is possible to conclude that all the article's objectives were reached by verification of the hypotheses, proven through empirical research and round table discussions.

After counting up the weights of importance assigned by the employees to their employers' contribution to further education, language courses and professional internships during the research, the highest importance among all benefits evaluated by the employees was gained by education.

In connection with the above findings, and confirmed also by round table discussions, the fact that the funds planned for education and trainings are usually among the first ones selected by companies for cost cutting is alarming.

Regardless of the fact that it negatively influences employee motivation, it is also a very short-sighted solution with negative consequences to appear later on. It is possible, based on practical and theoretical experience, to come to the conclusion that these consequences will impact employee productivity. Decreased work performance and employee demotivation can also negatively influence financial companies' clients, leading to dissatisfaction with the provided services and a potential shift to the competition.

The article has also investigated a highly relevant theme, one which still lacks enough attention in the Czech Republic - both in the scientific field and in business irrespective of its indisputable importance.

\section{References}

Armstrong, M. (1999). Personální management. Praha: Grada Publishing.

Bandura, A., Locke, E. A. (2003). Negative Self - Efficacy and Goal Effects Revise. Journal of Applied Psychology, 88 (1): 87- 99.

Beam, B. T., McFadden, J. J. (2001). Employee Benefits. Chicago : Dearborn Trade Publishing.

Frese, M., et al. (2007). Business Owners Action Planning and its Relationship to Business Success in Three African Countries. Journal of Applied Psychology, 92(6): 1481-1498.

Hong, J. Ch., Yang, S. D., Wan, l. J., Cchiou, E. F., Su, F. Y., Huang, S. L. (1995). Impact of Employee Benefits on Work Motivation and Productivity. International Journal of Career Management, 7(6): 10-14.

Joo, S. H., Grable, J. E. (2000). Improving Employee Productivity: The Role of Financial Counselling and Education. Journal of Employment Counselling. 37(1): 2-15.

Kanfer, R., Chen, G., Pritchard, R. D. (2008). Work Motivation: Past, Present, and Future. USA: Tailor and Francis Group.

Kleibl, J., et al. (2005). Personální řizení 2. Praha : Oeconomica, 2005

Landy, F. J., Conte, J. M. (2010). Work in the 21st Century: an Introduction to Industrial and Organizational Psychology. Malden : Blackwell Publishing.

Locke, E. A., Latham . P. (2002). Building a Practically Useful Tudory of Goal Setting and Task Motivation: A 35 - Year Odyssey. American Psychologist, 57(9): 705- 717.

Vancouver, J. B. (2005). The Depth of History and Explanation as Benefits and Bane for Psychological Control Theories. Journal of Applied Psychology, 90(1): 38-52.

\section{Author}

Ing. Iveta Němečková, Ph.D. Deputy Head of International Business Department University of Economics, Prague Winston Churchill Sq. 4, 13067

Prague 3, Czech Republic iveta.nemeckova@vse.cz

This article has been created with financial support of the Internal Grant Agency of the University of Economics, Prague, No. of project mF/13/2012. 